4 Chernik DA, Gillings D, Laine $H$, et al. Validity and reliability of the observer's assessment of alertness/sedation scale: study with intravenous midazolam. J Clin Psychopharmacol 1990; 10: 244-51.

\section{Preventing contamination of propofol infusions}

To the Editor:

Lorenz et al. ${ }^{1}$ examined the bacterial contamination rate of propofol syringes and infusions that were prepared according to: a) the manufacturer's strict guidelines for aseptic handling technique; and b) an alternate method of refilling syringes using what the authors refer to as a closed loop system. While the alternate method may be more efficient and economical, it cannot be properly described as a closed loop system because the stem of the syringe plunger may come into contact with the inside of the syringe during repeated filling. This is a potential source of contamination not associated with single use. Although the authors detected no difference in bacterial contamination rates between the two methods, the sample size of 80 patients is small and we remain concerned that anesthesiologists will endanger patients and assume increased medico-legal risks if they do not follow the manufacturer's recommended procedure.

Thomas Hackmann MD FRCPC

Chris S. Soder MD FRCPC

Halifax, Nova Scotia

\section{Reference}

1 Lorenz IH, Kolbitsch C, Lass-Flörl C, et al. Routine handling of propofol prevents contamination as effectively as does strict adherence to the manufacturer's recommendations. Can J Anesth 2002; 49: 347-52.

\section{REPLY:}

We welcome the comments by Drs. Hackmann and Soder on our article. ${ }^{l}$ We agree that the stem of the syringe plunger may come into contact with the inside of the syringe during repeated filling and that this is a potential source of contamination. We wish to clearly state that the main intention of this study was to subject the manufacturer's as yet unvalidated recommendations to a scientific study of the frequency of contamination of propofol syringes. It was in no way our intention to recommend that propofol be handled in a manner that deviates from the manufacturer's recommendations.
Christian Kolbitsch MD

Innsbruck, Austria

\section{Reference}

1 Lorenz IH, Kolbitsch C, Lass-Florl C, et al. Routine handling of propofol prevents contamination as effectively as does strict adherence to the manufacturer's recommendations. Can J Anesth 2002; 49: 347-52.

\section{Short-and long-term efficacy of oral ketamine in eight chronic-pain patients}

To the Editor:

Ketamine, as a $\mathrm{N}$-methyl-D-aspartate antagonist, has a noticeable analgesic action and can be used for the treatment of neuropathic pain. ${ }^{1-3}$ We studied the effect of oral ketamine in eight chronic neuropathicpain patients.

Patients relieved by the iv infusion of ketamine were entered in the study (Table). After informed consent had been obtained, eight patients were randomly assigned to receive oral ketamine syrup $\left(0.5 \mathrm{mg} \cdot \mathrm{kg}^{-1}\right)$ or the same volume of a placebo syrup every six hours for a week. After seven days the pain was rated by the patient on a visual analogue scale, and allodynia was rated on a four-point verbal rating scale. The plasma concentration of ketamine was measured at five, ten, $30,60,120$, and $180 \mathrm{~min}$ after its administration in all patients on the seventh day. In this short-term study, the severity of the pain and allodynia was reduced by oral ketamine administration about $15 \mathrm{~min}$ after administration, and improvement lasted from six to eight hours. Two of the eight subjects complained of headache relieved by loxoprofen. One patient complained of nightmares reduced by the coadministration of diazepam and of slight dizziness that required no treatment. Ketamine plasma levels were below the limit of detection $\left(0.05 \mu \mathrm{g} \cdot \mathrm{mL}^{-1}\right)$ in all patients despite good pain relief.

In addition, we assessed pain relief and side effects in four of eight patients treated with oral ketamine for more than nine months. We also measured the plasma concentration of ketamine $12 \mathrm{hr}$ after oral administration in two patients. In the long-term study, the severity of pain during daily life was reduced in all four patients (Table). We could reduce the dose of oral ketamine in two patients and of other analgesics in all patients. The plasma concentration of ketamine was $0.46 \mu \mathrm{g} \cdot \mathrm{mL}^{-1}$ in patient one and under the limit of detection in patient four. 